\author{
УДК 338.49 \\ УПРАВЛЕНИЕ СПОРТИВНОЙ ИНФРАСТРУКТУРОЙ МОНОГОРОДА НА ОСНОВЕ КОНЦЕПЦИИ \\ ФАСИЛИТИ МЕНЕДЖМЕНТА \\ Андрей В. Литвин ${ }^{1,}$,, Александра П. Ложкина ${ }^{1,}$ 2, Никита Э. Михайлов ${ }^{1,}{ }^{3}$ \\ ${ }^{1}$ Удмуртский государственный университет, 426034, Россия, г. Ижевск, ул. Университетская, 1 \\ @11itvin-andrey@mail.ru \\ @2lozhkinaap@mail.ru \\ @3nikitosski.91@mail.ru
}

Поступила в редакичию 30.01.2018. Принята к печати 17.04.2018.

\section{Ключевые слова:}

моногород, спортивная

инфраструктура, бюджет,

фасилити менеджмент, объект, эксплуатация, текущие затраты.

\begin{abstract}
Аннотация: Несмотря на общее улучшение экономического положения моногородов, состояние отдельных направлений социальной сферы в них, в частности спортивной, остается крайне нестабильным. Это, прежде всего, характерно для депрессивных регионов, где большинство объектов спортивной инфраструктуры либо выведены из организационной структуры градообразующего предприятия и существуют как самостоятельные, либо переданы непосредственно на баланс города, который в силу ограниченности местного бюджета не может в полной мере покрывать расходы по содержанию и эксплуатации этих объектов. В статье на примере одного из моногородов Удмуртской республики (г. Глазов), рассматривается относительно новая модель управления объектами спортивной инфраструктуры, базирующаяся на принципах фасилити менеджмента (Facility management). Фасилити менеджмент - один из методов практического менеджмента, рассматривающий любой объект недвижимости комплексно, с разных сторон, а именно технической, инфраструктурной и коммерческой. Основная цель данного метода - снижение текущих затрат при эксплуатации объекта, а также создание комфортных условий для пользователей за счет внутренних инфраструктурных изменений и сокращения непроизводственных потерь времени персоналом организации, работающим в данном спортивном сооружении. Проведенный анализ показал, что использование такого подхода позволяет существенно снизить текущие затраты на содержание объектов и, как следствие, расходную часть муниципального бюджета.
\end{abstract}

Для цитирования: Литвин А. В., Ложкина А. П., Михайлов Н. Э. Управление спортивной инфраструктурой моногорода на основе концепции фасилити менеджмента // Вестник Кемеровского государственного университета. Серия: Политические, социологические и экономические науки. 2018. № 3. С. 108-112. DOI:10.21603/2500-3372-2018-3-108-112.

В современной России значительная часть социально ориентированных отраслей народного хозяйства испытывают серьезные трудности бюджетного финансирования, несмотря на принимаемые на федеральном, региональном и муниципальном уровнях программы поддержки и развития данной сферы [1]. Это объясняется существовавшим ранее остаточным принципом финансирования, а также непродуманными, неэффективными реформами, заметно снизившими ресурсные возможности и потенциал региональных и муниципальных социальных комплексов.

Не является исключением в этом отношении и спортивная сфера, и более того, переход на региональный принцип управления спортом еще сильнее обострил эту проблему. Сегодня каждый регион (муниципалитет) готов сам определять (и определяет) основные направления своей спортивной политики, объемы финансирования, исходя из местных условий, традиций, наличия спортивной инфраструктуры, её технической оснащенности, превалирующей формы собственности. Несмотря на значительное укрепление за по- следние годы финансовой базы многих региональных (муниципальных) спортивных организаций, основные средства по-прежнему поступают в основном из бюджетов различных уровней, и все меньше от меценатов и спонсоров, даже при том что последние финансируют спорт из личных амбиций или даже альтруистических побуждений, не надеясь получить что-либо взамен. Данная ситуация очень рискованна для регионального и муниципального спорта, так как по мере рационализации управления на всех уровнях обоснованность расходования финансовых ресурсов будет контролироваться все жестче и жестче [2].

В связи с этим вопросы оптимального управления спортивной инфраструктурой, снижения коммунальных расходов и других затрат на содержание и эксплуатацию спортивных объектов, особенно для моногородов депрессивных регионов России, представляются достаточно актуальными.

Известно, что муниципальные образования - это самые большие обладатели объектов недвижимости, особенно нежилой, в которых располагаются учреждения 
образования, культуры, физической культуры и спорта и т. д. Причем практически все затраты на содержание и эксплуатацию этих объектов несет местный бюджет. Например, ежегодные расходы большинства муниципалитетов только в части оплаты основных коммунальных услуг (водоснабжение и водоотведение, электроэнергия, отопление) составляют от $23 \%$ до $37 \%$ [3]. Такая ситуация заставляет собственника разрабатывать, принимать и реализовывать соответствующие программные мероприятия, направленные на повышение энергетической эффективности и энергосбережения муниципальных объектов.

Однако попытки решить проблему таким образом во многих случаях потерпели неудачу, поскольку изначально предусматривали дополнительные инвестиции либо со стороны самого муниципалитета, либо со стороны частного бизнеса. В современных условиях свободных финансовых ресурсов у регионов-реципиентов и их муниципалитетов просто нет, а бизнес, не видя быстрой отдачи от таких инвестиционных проектов, предпочитает в них не участвовать [4].

Выход из ситуации видится во внедрении в практику управления муниципальной нежилой недвижимостью основных положений фасилити менеджмента (Facility management).

Фасилити менеджмент - метод практического менеджмента, который фокусирует внимание собственника объекта недвижимости (в нашем случае - муниципалитета) на всех сервисных процессах, происходящих внутри самого объекта, рассматривая последние с точки зрения формируемых ими затрат [5]. Иначе говоря, позволяет ответить на вопросы: все ли второстепенные работы и услуги организованы наилучшим образом, и можно ли за счет каких-либо мероприятий технического, инфраструктурного или коммерческого характера уменьшить затраты на их выполнение.

Содержание и эксплуатация любого объекта недвижимости сопровождаются множеством договоров с различными организациями: ресурсоснабжающими, контролирующими, сервисными, информационными, охранными и рядом других. Обычно за заключение, сопровождение, изменение договоров ответственны разные структурные подразделения учреждения, находящегося в объекте недвижимости, хотя и в пределах сметы расходов или лимитов, утвержденных муниципалитетом. Это приводит к дублированию отдельных управленческих функций, увеличению персонала и, как следствие, существенному увеличению затрат. Предлагаемый подход к управлению объектами недвижимости позволяет объединить традиционно проводимые отдельно сервисные работы и услуги, сделать более «прозрачными» сервисные процессы как в самом объекте муниципальной недвижимости, так и организации, в нем находящейся [6].

Фасилити менеджмент включает в себя сбор, архивирование, обработку и корректировку информации о ходе второстепенных сервисных процессов, протекающих в различных по своему функциональному назначению объектах недвижимости, с учётом формируемых затрат, имеющегося персонала и интересов владельца
[7]. Как следует из приведенного выше определения, это необходимо для создания условий и предпосылок к уменьшению затрат на содержание и эксплуатацию объекта недвижимости в будущем, а не сиюминутно. То есть можно характеризовать фасилити менеджмент как комплексную стратегическую концепцию по эффективному использованию всех материальных ресурсов, используемых организацией внутри и за пределами объекта недвижимости, которым она обладает. Материальные ресурсы или facilities - это земля, здания, приборы, машины и т.д. Эти ресурсы будут рассматриваться экономистом как средства производства, бухгалтером - как материальные активы, юристом - как движимое и недвижимое имущество. Субъектами исследования в фасилити менеджменте могут быть, например, самые различные по своему функциональному назначению здания: общественные, административные, производственные, торговые, офисные и другие [8].

Существенный аспект фасилити менеджмента - взаимоотношения между собственником и пользователем объекта недвижимости, так как они имеют прямо противоположные взгляды на него. Собственник или инвестор, построивший или купивший объект, планирует получать ренту, желательно как можно дольше. Арендатор или пользователь, наоборот, заинтересован в низкой арендной плате (эксплуатационных затратах) при использовании объекта, оптимальном выполнении всех производственных процессов при хорошем качестве сервиса. Например, пользователи муниципального спортивного объекта абсолютно не заинтересованы в реальной экономии каких-либо потребляемых ими ресурсов, за которые они либо не платят совсем, либо платят весьма условно; в обратном естественно заинтересован сам город, как собственник данного объекта.

Фасилити менеджмент рассматривает каждый объект недвижимости с трех направлений, позволяющих учесть все его архитектурные, строительные, технологические особенности комплексно, а именно технического, инфраструктурного и коммерческого (рисунок).

Техническое управление объединяет в себе работы и услуги, требующиеся для поддержания в работоспособном состоянии и эксплуатации строительных и технических систем и приборов по критериям энергоэффективности.

Инфраструктурное управление включает полный перечень второстепенных сервисных услуг, улучшающих качественное использование объекта недвижимости для его пользователей.

Коммерческое управление - это работы и услуги из предыдущих двух направлений, которые могут быть применены для извлечения дополнительной прибыли от сдачи в аренду временно свободных объемов и площадей объекта недвижимости.

Удмуртская Республика (УР) - типичный дотационный регион России со столицей в городе Ижевске и населением около 1,5 млн человек. Более 1 млн населения УР проживает в городах, три из которых - гг. Воткинск, Глазов и Сарапул - типичные монопрофильные города с населением около 100 тыс. человек. 


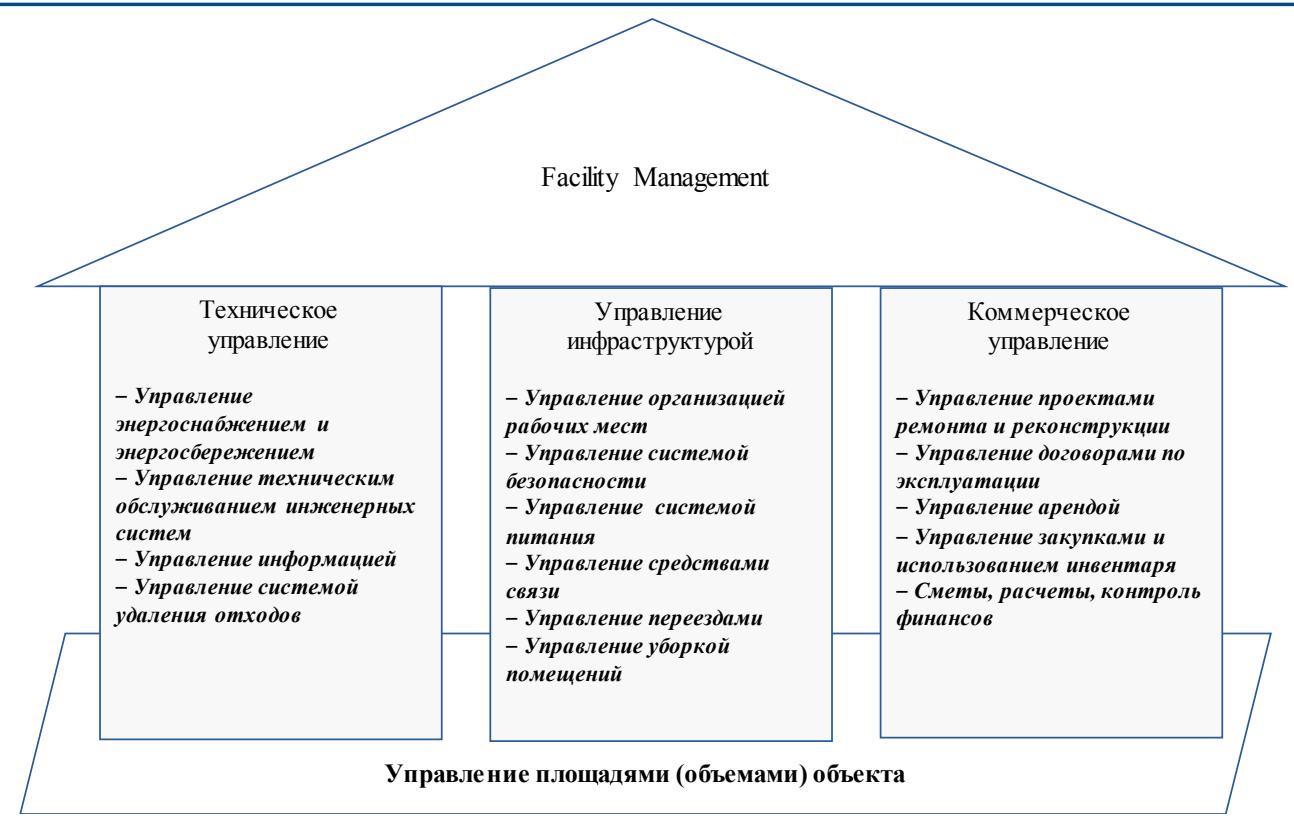

Рис. Содержание понятия фасилити менеджмент

Fig. Contents of the facility management concept

Основными составляющими спортивной инфраструктуры республики являются спортивные школы, спортивные здания и сооружения, их техническое состояние и пр., а главными показателями её развития - обеспеченность населения спортивными сооружениями, единовременная пропускная способность, величина выделяемых бюджетных средств, внебюджетные источники финансирования [9].

Город Глазов является городом республиканского значения Удмуртской Республики и по численности населения занимает четвертое место среди городов Удмуртской Республики. Численность населения города в 2017 г. составляла 97913 человек.

Градообразующим предприятием, от успешной работы которого зависит практически вся жизнедеятельность муниципального образования город Глазов, является ОАО «Чепецкий механический завод» (ОАО «ЧМЗ»). Это предприятие полного технологического цикла производства ядерного топлива, входящее в состав компании ОАО «ТВЭЛ». В ходе реорганизации ОАО «ЧМЗ» были выделены дочерние предприятия со своей производственной деятельностью и структурой. Производственных мощностей вспомогательных предприятий на сегодняшний день достаточно, чтобы продолжать обслуживать в полном объеме основное производство ОАО «ЧМЗ» и оказывать услуги предприятиям, организациям и населению города [10]. Следует, однако, отметить, что большинство объектов социальной сферы еще раньше были переданы на баланс города, в их числе все принадлежавшие предприятию спортивные сооружения, такие как ледовый дворец, стадион, плавательный бассейн.

Органом управления физической культурой и спортом в городе Глазове является отдел физической культуры и спорта Администрации муниципального образования «Город Глазов», в котором работают начальник, главный специалист-эксперт и три специалиста.
В 2017 г. спортивно-массовую и физкультурно-оздоровительную работу в городе проводили 155 штатных физкультурных работника, в том числе 51 тренер-преподаватель по 18 видам спорта, а также 34 совместителя и 16 помощников из числа представителей общественного физкультурного актива. 70 \% спортивных работников города имеют специальное высшее образование.

К систематическим занятиям физической культурой и спортом привлечено 26663 человека из числа взрослого населения, что составляет 27,2 \% (в 2016 г. - 24,2 \%, в 2015 г. - 23,1 \%) от численности жителей города, 462 инвалида и лиц с ограниченными возможностями здоровья, что составляет $6,04 \%$ (в 2016 г. - 3,56 \%) от общей численности данной категории граждан.

Среди граждан всех категорий и возрастов, занимающихся в секциях по видам спорта в физкультурных и спортивных организациях, наиболее популярными видами спорта являются: мини-футбол, хоккей, баскетбол, плавание, легкая атлетика, волейбол, лыжные гонки.

Большое значение в приобщении населения города к систематическим занятиям физической культурой и спортом имеет наличие спортивной инфраструктуры. Для проведения тренировочных и массовых спортивных мероприятий в городе имеется 147 спортивных сооружений, в том числе один стадион с трибунами, 5 плавательных бассейнов, 57 плоскостных спортсооружений, 65 спортивных залов. На сегодняшний день обеспеченность спортсооружениями в городе Глазове составляет: плоскостными - 27,6 \% (РФ - 57 \%, УР - 75,14\%), спортзалами - 40,42 \% (РФ - 49 \%, УР - 35,86 \%) [9].

Общий объем финансирования физической культуры и спорта за счет собственных средств бюджета муниципального образования составил в 2015 г. 37 635,6 тыс. руб.; в 2016 г. - 37078,0 тыс. руб., в 2017 г. 37 406,0 тыс. руб. В частности на оплату коммунальных услуг, текущее содержание и эксплуатацию муниципальных спортивных сооружений было предусмотрено 
в 2015 г. -7800,0 тыс. руб.; в 2016 г. - 8250,0 тыс. руб.; в 2017 г. - 9754,0 тыс. руб. Фактические же затраты по данной статье оказались выше в 2015 г. на 11,2\%, в 2016 г. - на 9,7\% и в 2017 г. - на 13,1\%, что объясняется увеличением цен (тарифов) на основные энергоносители, строительные и расходные материалы, а также других услуг по обеспечению текущей деятельности. Результат - недофинансирование отдельных мероприятий годового календарного плана, что повлекло за собой снижение количественных и качественных показателей работы спортивной сферы.

В качестве примера практической реализации концепции фасилити менеджмента был выбран муниципальный плавательный бассейн города, построенный в 1983 г. по стандартному проекту. В силу значительного морального и физического износа затраты на его содержание и эксплуатацию катастрофически нарастали год от года. Так, например, на оплату только основных коммунальных услуг (теплоснабжение, электроснабжение, водоснабжение и водоотведение) в 2016 г. было потрачено 1234,7 тыс. рублей, что на 11,3 \% больше по сравнению с предыдущим годом и на 19,8 \% по отношению к 2014 г. Средств на капитальный ремонт и реконструкцию данного объекта спортивной инфраструктуры в бюджете города на ближайшие три года не предусмотрено.

Не вдаваясь подробно в описание всех проведенных мероприятий и расчет экономического эффекта, отметим, что в техническом отношении основные предложения касались сокращения потребляемых зданием энергетических ресурсов (электрической и тепловой энергии, а также водоподготовки) и состояли в следующем: установка современного санитарно-технического оборудования, регулирующих клапанов, монтаж современных светодиодных светильников. Внедрение данных предложений позволило снизить соответствующие статьи затрат в среднем от 8 \% до $13 \%$ при сроке окупаемости, не превышающем полутора лет.
Проблемами инфраструктуры здания являлись управление системой питания (отсутствие возможности общественного питания персонала и посетителей, особенно в вечернее время), управление безопасностью (неэффективная система контроля входа-выхода пользователей), управление уборкой помещений (привлечение клининговой компании на принципах аутсорсинга), управление местами парковки (организация мест парковки на прилегающей территории), введение электронного документооборота. Решение вышеперечисленных проблем дает косвенный экономический эффект - сокращение непроизводственных потерь времени персоналом бассейна и посетителями.

В коммерческом управлении зданием был выделен один главный недостаток - неэффективное использование помещений. Были предложены и внедрены следующие мероприятия: управление площадями посредством информационной модели здания, что дало возможность использовать специализированные помещения более эффективно, например, залы сухого плавания и гимнастики); внедрение гибкой модели ценообразования на оказываемые услуги увеличило загрузку спортивного объекта в наиболее проблемное дневное время (с 11 до 14 часов). За счет данных предложений прибыль возросла на 5,3 \% по сравнению с предыдущим годом.

Таким образом, внедрение концепции и алгоритмов фасилити менеджмента на одном из муниципальных спортивных объектов позволило не только сохранить практически на прежнем уровне затраты на его содержание и эксплуатацию (фактические затраты за 2017 г. составили 1257,9 тыс. руб. вместо запланированных 1435,6 тыс. руб.), снизив нагрузку на местный бюджет, но и направить сэкономленные средства на решение других социальных задач, которых всегда очень много у любого монопрофильного города.

\section{Литература}

1. Стратегия развития физической культуры и спорта в Российской Федерации на период до 2020 года от 7 августа 2009 г. Постановление Правительства РФ №1101-р. Российская газета. 2009. № 178. С. 6-8.

2. Литвин А. В., Хазов А. Н. Facility management: теоретические основы и практический аспект // Вестник Удмуртского университета. Серия Экономика и право. 2003. № 1. С. 56-63.

3. Nävy J. Facility management: Grundlagen, Compüterunterstützung, Einführungsstrategie, Praxisbeispiele. Berlin: Springer Verlag, 2001, 327 p.

4. Талонов А. В. Управление инфраструктурой организации (фасилити менеджмент). М.: ГУУ, 2010,59 с.

5. Коттс Д. Управление инфраструктурой организации. М.: Типография «Новости», 2001. 597 с.

6. GEFMA, Deutscher Verband für Facility Management e.V. (GEFMA 100-1 Facility Management): GEFMA Richtlinie 100-1 Facility Management - Begriff, Struktur, Inhalte, Entwurf 07.2014, Bonn, 78 s.

7. Чувашов Е. В., Литвин А.В. Управление инфраструктурой (facility management) государственных образовательных учреждений // Российское предпринимательство. 2011. № 6-2. С. 148-153.

8. Литвин А. В. Сколько спортивных сооружений нужно муниципалитету? // Вестник УГТУ-УПИ. 2006. № 10. С. 25-27.

9. Удмуртия в цифрах. 2016 год: (стат. сб.) // Федер.служба гос. Статистики. Ижевск: Удмуртстат, 2017. 325 с.

10. Прогноз социально-экономического развития муниципального образования «Город Глазов» на 2017-2019 годы. Постановление Администрации муниципального образования «Город Глазов» № 9/42 от 03.11.2016 г. Газета «Красное знамя». 2016. № 47. С. 2-3. 


\title{
SPORTS INFRASTRUCTURE MANAGEMENT OF THE CITY BASED ON THE CONCEPT OF FACILITY MANAGEMENT
}

\author{
Andrei V. Litvin ${ }^{1, @ 1}$, Alexandra P. Lozhkina ${ }^{1,}$, Nikita E. Mikhailov ${ }^{1,3}$ \\ ${ }^{1}$ Udmurt State University, 1, Universitetskaya St., Izhevsk, Russia, 426034 \\ @1 litvin-andrey@mail.ru \\ @2lozhkinaap@mail.ru \\ @3nikitosski.91@mail.ru
}

Received 30.01.2018. Accepted 17.04.2018.

Keywords: monocity, sport infrastructure, local budget, facility management, real property, maintenance, operational costs.

\begin{abstract}
Despite the general improvement of the economic situation in one-industry urban settlements, the situation in some social spheres, such as sports, remains extremely unstable. It is typical of some depressive regions of Russia where the most sports infrastructure objects have been excluded from the organizational structure of the leading enterprise and exist as independent or even transferred to fixed assets of the monocities. The city can't cover all the expenses on maintenance and operation costs of these objects. The paper introduces a new model of management of sports infrastructure objects which is based on the principles of the facility management, as in the case of the town of Glazov (Udmurt Republic). Facility management is one of the methods of practical management considering real property from different ways, i.e. technical, infrastructure and commercial. The main objective of the method is to decrease current expenses at operation costs of real property. The analysis showed that the method lowers operational costs for the maintenance of the real property and reduces the load on the city budget.
\end{abstract}

For citation: Litvin A. V., Lozhkina A. P., Mikhailov N. E. Upravlenie sportivnoi infrastrukturoi monogoroda na osnove kontseptsii fasiliti menedzhmenta [Sports Infrastructure Management of the City Based on the Concept of Facility Management]. Bulletin of Kemerovo State University. Series: Political, Sociological and Economic Sciences, no. 3 (2018): 108-112. DOI:10.21603/2500-3372-2018-3-108-112.

\section{References}

1. Strategiia razvitiia fizicheskoi kul'tury i sporta v Rossiiskoi Federatsii na period do 2020 goda ot 7 avgusta 2009 g. [The strategy of development of physical culture and sports in the Russian Federation for the period until 2020 of August 7, 2009]. Decree of the Government of the Russian Federation No. 1101-r. Rossiiskaia gazeta $=$ Russian newspaper, no. 178 (2009): 6-8.

2. Litvin A. V., Khazov A. N. Facility management: teoreticheskie osnovy i prakticheskii aspect [Facility management: theoretical bases and practical aspect]. Vestnik Udmurtskogo universiteta. Seriia Ekonomika i pravo = Bulletin of the Udmurt University. Series Economics and Law, no. 1 (2003): 56-63.

3. Nävy J. Facility management: Grundlagen, Compüterunterstützung, Einführungsstrategie, Praxisbeispiele. Berlin, Springer Verlag, 2001, 327.

4. Talonov A. V. Upravlenie infrastrukturoi organizatsii (fasiliti menedzhment) [Management of the organization's infrastructure (facilitation management)]. Moscow: GUU, 2010, 59.

5. Kotts D. Upravlenie infrastrukturoi organizatsii [Infrastructure Management]. Moscow: Tipografiia «Novosti», $2001,597$.

6. GEFMA, Deutscher Verband für Facility Management e.V. (GEFMA 100-1 Facility Management): GEFMA Richtlinie 100-1 Facility Management - Begriff, Struktur, Inhalte, Entwurf 07.2014, Bonn, 78.

7. Chuvashov E. V., Litvin A.V. Upravlenie infrastrukturoi (facility management) gosudarstvennykh obrazovatel'nykh uchrezhdenii [Management of infrastructure (facility management) of state educational institutions]. Rossiiskoe predprinimatel'stvo = Journal of Russian Entrepreneurship, no. 6-2 (2011): 148-153.

8. Litvin A. V. Skol'ko sportivnykh sooruzhenii nuzhno munitsipalitetu? [How many sports facilities does a municipality need?]. Vestnik UGTU-UPI = Bulletin of the USTU-UPI, no. 10 (2006): 25-27.

9. Udmurtiia v tsifrakh. 2016 god: (stat. sb.) [Udmurtia in figures. 2016]. Feder.sluzhba gos. Statistiki [Feder.service state. Statistics]. Izhevsk: Udmurtstat, 2017, 325.

10. Prognoz sotsial'no-ekonomicheskogo razvitiia munitsipal'nogo obrazovaniia «Gorod Glazov» na 2017-2019 gody [Forecast of social and economic development of the municipal entity «The Town of Glazov» for 2017-2019]. Decree of the Administration of the municipal entity «City of Glazov» No. 9/42 of 03.11.2016. Gazeta «Krasnoe znamia» $=$ The newspaper «Red Banner», no. 47 (2016): 2-3. 